Determinants of Recent Immigrants ¿ Location Choices

\title{
Quasi-Experimental Evidence
}

Damm, Anna Piil

Publication date:

2005

Document version

Publisher's PDF, also known as Version of record

Citation for published version (APA):

Damm, A. P. (2005). Determinants of Recent Immigrantsi Location Choices: Quasi-Experimental Evidence.

Department of Economics, University of Copenhagen. 


\section{CAM}

\section{CAM}

Centre for Applied

Microeconometrics

Department of Economics

University of Copenhagen

http://www.econ.ku.dk/CAMI

Determinants of Recent Immigrants' Location

Choices: Quasi-Experimental Evidence

Anna Piil Damm

2005-17

The activities of CAM are financed by a grant from

The Danish National Research Foundation 


\title{
Determinants of Recent Immigrants' Location Choices: Quasi-Experimental Evidence*
}

\author{
Anna Piil Damm ${ }^{\dagger}$
}

October 14, 2005

\begin{abstract}
This paper exploits a Danish spatial dispersal policy on refugees which can be regarded a natural experiment to investigate the influence of regional factors on recent immigrants' location choices.

The main push factors are lack of co-ethnics and presence of immigrants. Additional push factors are lack of access to jobs, education and housing which explain why recent immigrants are attracted to large cities. Finally, placed refugees are sensitive to regional unemployment and some evidence of welfare seeking is presented as well.
\end{abstract}

JEL classifications: J15, R15 and H0.

Keywords: Location Choices, Push Factors, Immigrants.

\section{Introduction}

It is a common international phenomenon that the immigrant population is geographically concentrated. In 1990, $63 \%$ of the foreign born population in the United States were clustered in the four most populous states, California, New York, Florida and Texas, where only $31 \%$ of the overall population lived (Zavodny 1997). In 1998, 52\% of the

\footnotetext{
*Acknowledgement: I thank the National Centre for Register Research, the Ministry for Refugee, Immigration and Integration Affairs and the Institute of Local Government Studies for support to access data from Statistics Denmark. I would also like to thank Bente Bondebjerg and Morten Iversen, Danish Refugee Council, for valuable information about the Danish Dispersal Policy 1986-1998 and Peter Fredriksson for valuable methodological comments and suggestions. Finally, I thank participants at the ESPE Conference 2002 for their comments.

${ }^{\dagger}$ CAM and Aarhus School of Business, Department of Economics, Silkeborgvej 2, DK-8000 Aarhus C. Email: apd@asb.dk.
} 
foreign born population in Denmark lived in the metropolitan area where only $34 \%$ of the overall population lived (Ministry of Internal Affairs 1999).

Policymakers may believe that new immigrants are attracted to areas with large immigrant populations or that areas with low regional unemployment attract new immigrants. Knowledge of factors influencing location choices of recent immigrants helps local policymakers anticipate which locations can expect to receive immigrants in the future. In addition, legislators may want to consider potential effects of governmental policies on the location choices of new immigrants when changing policies.

Empirical investigation of immigrants' location preferences is not an easy task. Almost all previous studies investigate immigrants' location preferences using information on immigrants' first choice of location in the host country. However, estimates from a standard choice model will not reflect preferences, if individual-specific costs of choosing some regions over others are ignored. Suppose, for instance, that immigrants who are not proficient in foreign languages have higher costs of settlement outside an ethnic enclave than immigrants with foreign language proficiency. In that case, estimation of pull factors, i.e. the set of negative or positive social or economic factors in the potential areas of destination which pulls migrants towards them (Lee 1966), will be biased. An alternative way of learning about immigrants' location preferences is to estimate push factors, i.e. the set of negative or positive social or economic factors in an area of origin which pushes migrants away (Lee 1966), based on immigrants' subsequent internal migration pattern. However, in general push factor estimates may be biased due to location sorting, which is present if location characteristics of the area of origin are correlated with unobserved characteristics of the individual that also influence the migration probability. This is likely to be the case, because in general individuals choose location of residence themselves, in a non-random way, based on a number of determinants of migration some of which are unobserved to the researcher. To give an example, suppose that individuals who are not proficient in foreign languages are less prone to migrate. Suppose further that new immigrants who are not proficient in foreign languages are more likely to settle in the existing enclaves of co-ethnics in the hostcountry. Foreign language proficiency of new immigrants is usually unobserved to the researcher. In that case, the correlation between the probability of migration and ethnic enclave size may be driven by the unobserved factor, foreign language proficiency.

This study exploits quasi-experimental data to determine determinants of recent immigrants' location choices. The data stem from a governmental spatial dispersal policy on refugees in Denmark in 1986-1998. The dispersal policy allows us to circumvent the methodological problem of location sorting, because the policy implied that new refugees were randomly distributed across locations in Denmark conditional on six refugee characteristics largely observable in Danish administrative registers for the population of im- 
migrants. Controlling for these individual characteristics in the migration decision, the initial location can be regarded as exogenous in the subsequent migration decision. In this way the Danish spatial dispersal policy can be regarded as a natural experiment.

The paper takes advantage of the natural experiment to estimate push factors in placed refugees' subsequent migration decision. Due to the exogeneity of the initial location, the push factor estimates are unaffected by initial location sorting. In contrast, some of the estimated effects of demographic characteristics of the individual on the subsequent migration decision are correlations because they may have affected the initial location. Hence, they should not be given a causal interpretation and are therefore not reported.

An additional strength of the study is the data. We use Danish longitudinal micro data for the population of refugees which allow for reconstruction of the residential history of a refugee since the date of immigration. However, the location choice analysis is restricted to the first migration investment because of the exogeneity of the initial location in contrast to the endogeneity of subsequent locations. The main geographical unit of location used in the study is a municipality, because the Danish spatial dispersal policy aimed at an equal distribution of refugees, not only at the county level, but also at the municipality level. Hence, a move across the municipality border is regarded as a migration investment.

The next section presents theory and empirical findings from previous studies on immigrants' location choices. In Section 3, the institutional setting is described with emphasis on the first Danish spatial dispersal policy carried out between 1986 and 1998. In Section 4 , the methodology of the push factor analysis is presented. The section begins with a formalisation of the migration decision problem faced by placed refugees and continues with a presentation of the econometric specification of the migration model. Section 5 includes a short description of our micro data, descriptive evidence on placed refugees' subsequent migration pattern and a short description of area of origin data to be included as explanatory variables in the empirical models. In Section 6, the push factor estimates are presented. It is shown that the two main push factors are a relatively low percentage of his ethnic group that resides in the municipality of assignment and a relatively high percentage of immigrants and their descendants that resides in the municipality of assignment. In other words, placed refugees mainly react to lack of co-ethnics and presence of immigrants in the municipality of assignment. Finally, conclusions and policy implications are presented in Section 7. 


\section{Recent Immigrants' Location Choices: Theory and Previous Findings}

US studies on immigrants' location choice find the presence of co-ethnics to be an important determinant of immigrants' location choice (see e.g. Bartel 1989; Zavodny 1997; Jaeger 2000; Bauer et al. 2002a; Bauer et al. 2002b). Different theories have been put forward to explain why this is so. First, there is the ethnic network hypothesis according to which the presence of co-ethnics constitutes an ethnic network which facilitates new immigrants' adjustment to the new society (Piore 1979; Kobrin and Speare 1983). Specifically, residence in an ethnic enclave strengthens feelings of security, solidarity and identity within the group due to the common cultural background. Furthermore, the local ethnic network may establish social institutions that support its members in relation to the rest of the society. In addition, local ethnic labour markets may develop further employment opportunities. Finally, the ethnic network may convey information about employment opportunities outside the residential area. Second, there is the ethnic goods theory proposed by Chiswick and Miller (2005) which emphasises that living in an ethnic enclave reduces costs of consumption of so-called ethnic goods. Such goods are defined as the consumption characteristics of an ethnic group not shared with the host population, broadly defined to include market and non-market goods and services, including social interactions for themselves and their children with people of the same origin. Finally, there is the informational cascades or herd effects theory suggested by Epstein (2002). Herd effects in location choice may exist if migrants have some private information about different locations and observe previous emigrants' decisions, but are imperfectly informed about the attributes of the alternative locations and about the information signal that was driving previous emigrants' decisions. An important implication of herd effects is that they may result in inefficiences. Some empirical evidence in favour of each of these theories exists, see e.g. Bauer et al. (2002a) for supportive evidence of the ethnic network theory, Chiswick and Miller (2005) for empirical evidence of the ethnic goods theory and Bauer et al. (2002b) for empirical validation of the herd effects theory. Note however, that it is difficult to identify the effects of each of these three factors separately in econometric analyses.

Presence of immigrants is also found to be an important determinant in some of the US studies (Zavodny 1999; Jaeger 2000). Note however, that the study by Zavodny (1999) does not control for presence of co-ethnics. Jaeger (2000) offers a possible explanation, namely that immigrants may prefer "international neighbours", without regard to their country of origin.

A third demographic variable which has been found to attract new immigrants is 
local population size (Bartel 1989; Zavodny 1999; Jaeger 2000). Bartel (1989) offers the explanation that the local population size is correlated with job opportunities and general economic activity.

Migration theory predicts that there may be other determinants of immigrants' location decision than presence of co-ethnics and other immigrant groups, including economic factors such as regional unemployment, social benefit levels or eligibility rules or public goods provision if interregional differences exist. US studies have found contrasting evidence on this issue. Immigrants are found to be insensitive to local labour market conditions in Bartel (1989) whereas Jaeger (2000) finds that all visa categories of immigrants, except spouses of US citizens, are indeed sensitive to these conditions. Furthermore, the empirical studies by Zavodny (1997) and Borjas (1999) have investigated the so-called welfare magnets hypothesis, according to which new US immigrants are attracted to US states with a relatively generous welfare system. Using macro data, Zavodny (1999) finds no significant evidence of welfare seeking influencing immigrants' settlement decision. In contrast, using micro data, Borjas (1999) finds that immigrant welfare recipients are much more likely to be geographically clustered in high-benefit states, notably in California, than immigrants who do not receive social benefits, and that they are more clustered than natives. However, controlling for other factors which may potentially have influenced the location decision, Borjas (1999) finds only weak empirical evidence of welfare magnets in the sense of lack of statistical significance of the results.

Little research exists on the location choice of immigrants outside the US. The empirical study by Åslund (2005) on the initial and subsequent location of immigrants to Sweden during the 1980s is an important exception. Empirical findings of that study show that refugees tend to leave locations with high overall unemployment and are attracted to regions in which co-ethnics and other immigrants live and to regions with high immigrant employment rates and high average earnings. On the other hand, Åslund finds no evidence of direct welfare seeking. Note that the study by Åslund (2005) uses quasi-experimental micro data that stem from the Swedish spatial dispersal policy on new refugees carried out in the late 1980s. Åslund shows that using data with exogenous initial location is important for estimating the effects of local characteristics on subsequent migration; endogenous location leads to underrating of their importance due to the initial sorting across locations.

\section{The Institutional Setting}

Subsection 3.1 briefly describes the geographical settlement pattern of the immigrant population in Denmark prior to the implementation of the first spatial dispersal policy on 
refugees in Denmark. In Subsection 3.2, main features of the first spatial dispersal policy are presented.

\subsection{Geographical Settlement Pattern of Immigrants}

Denmark is administered at three levels: the state, the county and the municipal level. Denmark has 275 municipalities; 273 of the municipalities constitute 14 counties. Copenhagen and Frederiksberg municipalities are excluded from the county division (Statistics Denmark 1997, 39).

Table 1

Geographic distribution of the overall Danish population and of immigrants across counties in 1985. Per cent.

\begin{tabular}{lll}
\hline \hline Subgroup: & All & Immigrants \\
\hline County: & & \\
Copenhagen and Frederiksberg municipalities & 10.96 & 28.78 \\
Copenhagen & 11.91 & 19.62 \\
Frederiksborg & 6.59 & 8.94 \\
Roskilde & 4.14 & 3.50 \\
West Zealand & 5.48 & 3.35 \\
Storstroem & 5.03 & 2.57 \\
Bornholm & 0.92 & 0.33 \\
Funen & 8.90 & 5.97 \\
Southern Jutland & 4.88 & 5.06 \\
Ribe & 4.22 & 2.22 \\
Vejle & 6.40 & 3.54 \\
Ringkoebing & 5.18 & 2.04 \\
Aarhus & 11.44 & 8.75 \\
Viborg & 4.51 & 1.38 \\
Northern Jutland & 9.43 & 3.94 \\
All & 100.00 & 100.00 \\
Frequencies & $5,116,153$ & 183,968 \\
\hline \hline
\end{tabular}

Source: Longitudinal administrative registers of Statistics Denmark on the immigrant population in Denmark 1984-2000. 
Table 1 presents the distribution of the overall Danish population and of the immigrant population (immigrants and their descendants) across counties in 1985, i.e. the year before the implementation of the first dispersal policy on refugees in Denmark. In 1985, immigrants were highly overrepresented in Copenhagen and Frederiksberg municipalities and Copenhagen County that constitute the Greater Copenhagen area (metropolitan area) and, in addition, a neighbouring county of Copenhagen County, Frederiksborg County.

\subsection{The Danish Spatial Dispersal Policy 1986-1998}

1986 marks the start of the first Danish spatial dispersal policy on refugees and asylum seekers who had just received a permit to stay for reasons of asylum. ${ }^{1}$ Henceforth, we refer to such recognized refugees and asylum seekers as refugees. The Danish Government urged the Danish Refugee Council to implement the dispersal policy after a surge of refugees in the mid-eighties made it increasingly difficult for the Council to satisfy the location preferences of most new refugees for accommodation in the larger cities. The policy was in force until 1999 under the charge of the Council. The Council's assignment policy aimed at promoting an equal share of refugees in all counties. At the county level, the Council aimed at attaining an equal share of refugees in municipalities (local authority districts) with suitable facilities for reception such as housing, educational institutions, employment opportunities, and co-ethnics. In practice, these dispersal criteria implied that refugees were provided with permanent housing in cities and towns and to a lesser extent in the rural districts (Ministry of Internal Affairs 1996). In 1987, 243 out of a total of 275 municipalities in Denmark had received refugees (Danish Refugee Council 1987).

Dispersal was voluntary in the sense that only refugees who were unable to find housing themselves were subject to the dispersal policy. However, the take-up rate was high; between 1986 and 1997 approximately 90\% of refugees were provided with permanent housing by the Council (or after 1995 by a local government) under the terms of the dispersal policy (Annual Reports of the Danish Refugee Council 1986-1994 and the Council's internal administrative statistics for 1995-1998).

Once settled, refugees participated in Danish language courses during an introductory period of 18 months while receiving social assistance. Refugees were urged to stay in the assigned municipality during the entire introductory period. However, there were no relocation restrictions. Refugees could move away from the municipality of assignment at

\footnotetext{
${ }^{1}$ Until June 2002, Denmark gave asylum to Convention refugees, i.e. persons who were defined as refugees according to the Geneva Convention from 1951, and to foreigners who were not defined as refugees according to the Geneva Convention, but who for similar reasons as stated in the Convention or other weighty reasons should not be required to return to the home country ('de facto' refugees). [Coleman and Wadensjö 1999, 249].
} 
any time, in so far as they could find alternative housing elsewhere. Receipt of welfare was unconditional on residing in the assigned municipality.

The dispersal policy did, at least in the short run, influence the location pattern of refugees. In 1993, the settlement pattern of refugees resembled that of the Danish population and differed greatly from that of non-western immigrants. 33\% of refugees and $26 \%$ of the Danish population lived in the capital or its suburbs while as much as $71 \%$ of non-western immigrants lived there. $56 \%$ of refugees and $59 \%$ of the Danish population lived in towns outside the capital as opposed to only $24 \%$ of non-western immigrants. The remaining shares lived in rural districts (Danish Refugee Council 1993).

Damm (2005) argues that the Danish spatial dispersal policy 1986-1998 gave rise to a random initial residential distribution of refugees who were provided permanent housing by the Council, conditional on seven characteristics of the individual at the time of assignment: family size, health (in need of special treatment of medical or mental health problems), special educational needs, the location of close relatives, nationality (some nationalities were more likely to be placed in a large city than others), year of immigration (over time it became increasingly difficult for the Council to find housing in the larger and medium-sized towns) as well as reluctance to accept assignment to a nonpreferred county. These governing factors suggest that non-single refugees with special health treatment and educational needs and refugees with close family in Denmark near whom they were determined to live and who arrived early in the observation period were most likely to realise their preferred settlement option.

\section{Methodology}

The migration decision problem faced by a placed refugee is formalised in Subsection 4.1. In Subsection 4.2, the econometric specification of the migration model is presented.

\subsection{Migration Model}

A placed refugee faces a problem of finding an optimal location in the host country, i.e. he has to decide whether or not to move away from the municipality of assignment. We model the migration decision in line with the human capital model according to which migration is viewed as an investment that is expected to pay off in the form of increased earnings or other kinds of pecuniary or non-pecuniary returns (Sjaastad 1962; Bowles 1970). Nonmoney returns include changes in "psychic benefits" as a result of location preferences. Similarly, costs include both money and non-money costs, such as costs of transport and psychic costs, respectively. We model the migration decision as if the potential migrant weights the net expected pecuniary and mental benefits of moving against the expected 
pecuniary and mental costs of moving. Migration will occur, if the former exceeds the latter. The model presented is similar to the migration model by Nakosteen and Zimmer (1980).

Let $U_{i 1}$ denote the expected utility of individual $i$ in location 1 , the potential municipality of destination. Similarly, let $U_{i 0}$ denote the utility of individual $i$ in location 0 , the municipality of assignment. $C_{i}$ denotes the expected moving costs which are assumed to be the same across destinations but not across individuals.

Individual $i$ chooses to migrate if

$$
M_{i}^{*}>0
$$

and doesn't migrate if

$$
M_{i}^{*} \leq 0
$$

where

$$
M_{i}^{*}=\alpha_{0}+\alpha_{1}\left(U_{i 1}-U_{i 0}\right)-C_{i}-\varepsilon_{i}
$$

$\alpha$ are parameters to be estimated and $\varepsilon_{i}$ is a stochastic error term. According to the migration decision equation (3), the migration propensity increases linearly with the expected gains in utility and decreases linearly with the expected costs of migration. However, the utility levels and expected costs of migration are not directly observed. Assume that they are given by the following linear relations

$$
\begin{gathered}
U_{i 1}=\theta_{01}+X_{i}^{\prime} \theta_{11}+Z_{i}^{\prime} \theta_{21}+\varepsilon_{i 1} \\
U_{i 0}=\theta_{00}+X_{i}^{\prime} \theta_{10}+Z_{i}^{\prime} \theta_{20}+\varepsilon_{i 0} \\
C_{i}=\gamma_{0}+X_{i}^{\prime} \gamma_{1}+Z_{i}^{\prime} \gamma_{2}+\varepsilon_{i c}
\end{gathered}
$$

where $X$ is a vector of personal attributes of individual $i$ and $Z$ is a vector of regional attributes of the origin locality and $\theta$ and $\gamma$ are parameters to be estimated. $\varepsilon_{i 1}, \varepsilon_{i 0}$ and $\varepsilon_{i c}$ are stochastic error terms. Equations (3)-(6) comprise the basic structural form of the model. Substituting (4)-(6) into (3) gives the reduced form of the migration decision equation:

$$
M_{i}^{*}=\beta_{0}+X_{i}^{\prime} \beta_{1}+Z_{i}^{\prime} \beta_{2}-\varepsilon_{i}^{*}
$$

Then individual $i^{\prime} s$ probability of migration is given as 


$$
\operatorname{Pr}\left(M_{i}^{*}>0\right)
$$

We do not observe $M^{*}$, but only

$$
M_{i}=1 \text { if } M_{i}^{*}>0
$$

and

$$
M_{i}=0 \text { if } M_{i}^{*} \leq 0
$$

The variables included in the vectors $X$ and $Z$ are described in Section 5 .

\subsection{Econometric Specification}

\subsubsection{Mixed Proportional Hazard Model}

The binary nature of the observed dependent variable in equation (9) suggests that the parameters in the migration decision equation (7) could be estimated by maximum likelihood probit or logit techniques. Estimation of a probit or logit model would provide us with estimates of the determinants of having migrated at a specific point in time. Instead we will specify the theoretical model as a duration model to estimate the determinants of migrating at a specific point in time, conditional on having resided in the municipality of assignment up to this point in time.

Let the random variable $T$ denote time until exit from the municipality of assignment. Let $X$ be the vector of initial values of personal attributes of individual $i$ and $Z$ be the vector of initial values of regional attributes of the municipality of assignment. Let $v$ be time-invariant unobserved heterogeneity of individual $i$. Subscript $i$ is suppressed below for notational simplicity.

The key variable in duration models is the hazard rate which in continuous time is defined as the transition rate out of the state of interest at time $t$, conditional on being in the state at least until $t$, i.e.

$$
h(t)=\lim _{d t \rightarrow 0} \frac{P(t<T \leq t+d t \mid T>t)}{d t}
$$

The hazard function for exit from the municipality of assignment is specified as a mixed proportional hazard (MPH) model

$$
h(t \mid X, Z, v)=\lambda(t) \cdot \exp \left(X^{\prime} \beta_{1}+Z^{\prime} \beta_{2}+v\right)
$$


$\lambda(t)$ denotes the baseline hazard which captures duration dependence and $\exp \left(X^{\prime} \beta_{1}+\right.$ $\left.Z^{\prime} \beta_{2}+v\right)$ is a scale function which captures the effect of observed and unobserved individual-specific characteristics. ${ }^{2}$

The likelihood contribution of a completed residential spell is given by the density

$$
f(t \mid X, Z, v)=h(t \mid X, Z, v) \exp \left(-\int_{0}^{t} h(u \mid X, Z, v) d u\right)
$$

while the likelihood of a right-censored residential spell is given by the probability of no exit until time $t$

$$
S(t \mid X, Z, v)=\exp \left(-\int_{0}^{t} h(u \mid X, Z, v) d u\right)
$$

where $S(t \mid X, Z, v)$ is the survivor function.

Definition of a non-censoring indicator $d$ that takes the value 1 if a residential spell is not right-censored and 0 otherwise then allows us to write the likelihood contribution of a residential spell as

$$
L=h(t \mid X, Z, v)^{d} \exp \left[-\int_{0}^{t} h(u \mid X, Z, v) d u\right]
$$

We choose a flexible model for the unobserved covariates. Let $G$ denote the cumulative distribution function for the unobserved covariate in the hazard rate, $v$. Then the total likelihood contribution from a residential spell of an individual is the product of the likelihood contribution of the residential spell integrated over the distribution of the unobserved covariates

$$
L=\int_{v} L(t \mid X, Z, v) d G(v)
$$

The intuition is that because an individual's type is not known, the likelihood function is a mixture over types weighted by their sample probabilities (Heckman and Singer 1984).

The marginal distribution of the unobserved term is specified as a discrete distribution with two unrestricted mass point locations. Let $v^{m}, m=1,2$ denote the two mass-points of $v$. Each combination is observed with probability $p_{i}$ to be estimated, with $0 \leq p_{i} \leq 1$ for $i=1,2$ and $\sum_{i=1}^{2} p_{i}=1$. We normalise the distribution of the unobserved term by letting $v^{1}=0$.

The baseline hazard function is assumed to be piecewise constant, i.e. $\lambda(t)=\exp \left(\alpha_{k}\right), k=$ $1, \ldots, K$, where $K$ is the number of intervals of the baseline hazard function. The length of the baseline intervals is chosen by inspection of the empirical hazard function for exit from the municipality of assignment, plotted in Figure 1 in Subsection 5.1.

\footnotetext{
${ }^{2}$ The main functional form implication of the proportional hazard model is that covariates are assumed to have a proportional effect on the baseline hazard.
} 


\subsubsection{Model Identification}

Given normalisations of the mean of the unobserved covariates (finite means) and weak requirements for variation in the observed covariates, the MPH model is identified nonparametrically if the observed covariates are independent of unobserved characteristics influencing the outcome of interest, i.e. the probability of out-migration (Elbers and Ridder 1982). In particular, the latter identification condition implies that initial settlement is independent of any unobservable individual-specific characteristic in the outcome equation. This requirement is satisfied if the refugee characteristics which have influenced the initial settlement are observable so that we can control for them in the model.

As mentioned in Subsection 3.2, the related study Damm (2005) concludes that the initial settlement of new refugees may have been influenced by family size, health, special educational needs, location of close relatives, nationality, year of immigration as well as reluctance to accept assignment to a non-preferred county. Three of these characteristics are observed in Danish administrative registers (to be described in Subsection 5.1): family status (measured by marital status and indicator variables for having children aged 0-2 and having children aged 3-17), nationality, and year of immigration. Moreover, Damm (2005) argues that age and nationality may be decent proxies for special educational needs, and that nationality and size of the ethnic stock may be decent proxies for whether the individual had relatives in Denmark at the time of assignment. In contrast, the registers do not contain any decent proxy for need of special treatment for medical or mental health problems. However, there was no systematic mental health examination of refugees at the time of assignment. Furthermore, since mental health problems are taboos, they tend to be treated at a late stage, if treated at all. Whether a refugee was in need of special mental treatment at the time of assignment is therefore likely to have had little influence on initial settlement. Reluctance to accept assignment to a non-preferred county is probably of minor importance: the combination of high take-up rates and low reassignment rates indicates that only a small fraction of the refugees insisted on living in a particular area.

Hence, the data at hand enables us to condition on the variables which may have had a significant influence on the initial settlement of an individual. Therefore, it seems reasonable to assume that regional attributes of the area of origin are independent of unobserved characteristics of the individual. Consequently, the condition for identification of area of origin covariates is satisfied. 


\section{Data}

Our micro data is described in Subsection 5.1. Subsection 5.2 presents descriptive evidence on placed refugees' initial settlement and subsequent migration pattern. Area of origin data is presented in Subsection 5.3.

\subsection{Refugee Sample}

Micro data on refugees is extracted from longitudinal administrative registers of Statistics Denmark on the immigrant population in Denmark 1984-2000, henceforth referred to as the immigrant data set. Our sample selection criteria result in a refugee sample with information on 36,718 individuals of which 21,708 are men. Ideally, this sample should cover observations on all adult refugees who were assigned to a municipality by the Council under the terms of the spatial dispersal policy carried out 1986-1998. However, information on admission category of immigrants and the assignment municipality of refugees is missing in the registers.

We take account of the first issue by applying an algorithm based on country of origin and the first year of residence permit to Denmark to extract individuals from the 17 largest refugee-sending countries who immigrated between Oct. 1985 and Dec. 1997. The algorithm was constructed from official figures on the annual number of residence permits granted to refugees by country of origin. The validity of the algorithm was investigated in Damm (2005) by comparison of the ethnic composition of the extracted sample by year of immigration, presented in Table A.1 in the Appendix, with the ethnic composition of refugees granted asylum for each year according to official statistics published by Statistics Denmark. The algorithm was found to be valid, since the ethnic composition of the sample is consistent with the official ethnic composition of the refugee group, except that a few refugee-sending countries from which only a small number of refugees originate are left out of the extracted sample.

Solving the second data issue is further complicated by the fact that refugees may initially have lived in temporary housing in proximity of the municipality to which they were later assigned, on average after 1 year and in general after 3 months. This is the reason for which we include refugees who immigrated in the last quarter of 1985 in the refugee sample. We identify the municipality of assignment by using a rather complicated algorithm which we constructed based on information on the Council's internal administrative statistics on temporary housing. We define the first municipality of residence observed in the registers as a municipality of temporary housing if the person relocates to another municipality within the county within one year after receipt of residence permit. Otherwise the first municipality is defined as the municipality of assignment. 
Table 2

Descriptive statistics on residential spells.

\begin{tabular}{l|lll}
\hline \hline Residential spell & Frequency & Distr. (\%) & Mean duration \\
\hline Completed & 14,326 & 39.02 & $27.92(27.05)$ \\
Right-censored & 22,392 & 60.98 & $74.10(42.67)$ \\
All & 36,718 & 100.00 & $56.08(43.63)$ \\
\hline \hline
\end{tabular}

Notes: Standard deviations are reported in parentheses.

Furthermore, we want to exclude family-reunified immigrants from refugee-sending countries, because they were not subject to spatial dispersal, unless they immigrated shortly after their spouse. We therefore exclude immigrants from refugee-sending countries, who at the time of immigration were married to one of the following: 1) an individual born in Denmark, 2) an immigrant from a non-refugee-sending country or 3) an immigrant from a refugee-sending country who had immigrated at least one year earlier. We exclude individuals who were neither observed in the registers in the year of immigration nor in the following year, because in that case information on the initial municipality of residence is missing. Unfortunately, the registers do not allow us to exclude the $10 \%$ of refugees who turned down the Council's offer of housing under the terms of the spatial dispersal policy. Finally, we include only individuals aged 18-66. The data set is informative about an individual's county and municipality of residence (at the end of each year) and the date of the last residential move (by the end of each year). Such information is available because in Denmark it is determined by law to report your residential move to the local municipality of destination within a fortnight after the move. These variables enable us to construct spells for municipality of residence for each individual. The duration of these spells is measured in months. Since the analysis concerns determinants of the first migration investment after placement, we only follow an individual until the end of the first spell, i.e. until an individual moves away from the initial municipality of residence or until the end of year 2000 if the first spell is right-censored.

Descriptive statistics on residential spells are reported in Table 2. There is one residential spell per individual in the refugee sample, namely the spell of residence in the municipality of assignment. By 2000, 39\% of the individuals have moved out of the municipality of assignment. On average, movers make the first migration investment 28 months after settlement in the municipality of placement. As one would expect, the share of movers is negatively correlated with the year of immigration: $58 \%$ of 1986 cohort of refugees are movers compared to only $26 \%$ of the 1997 cohort of refugees. 


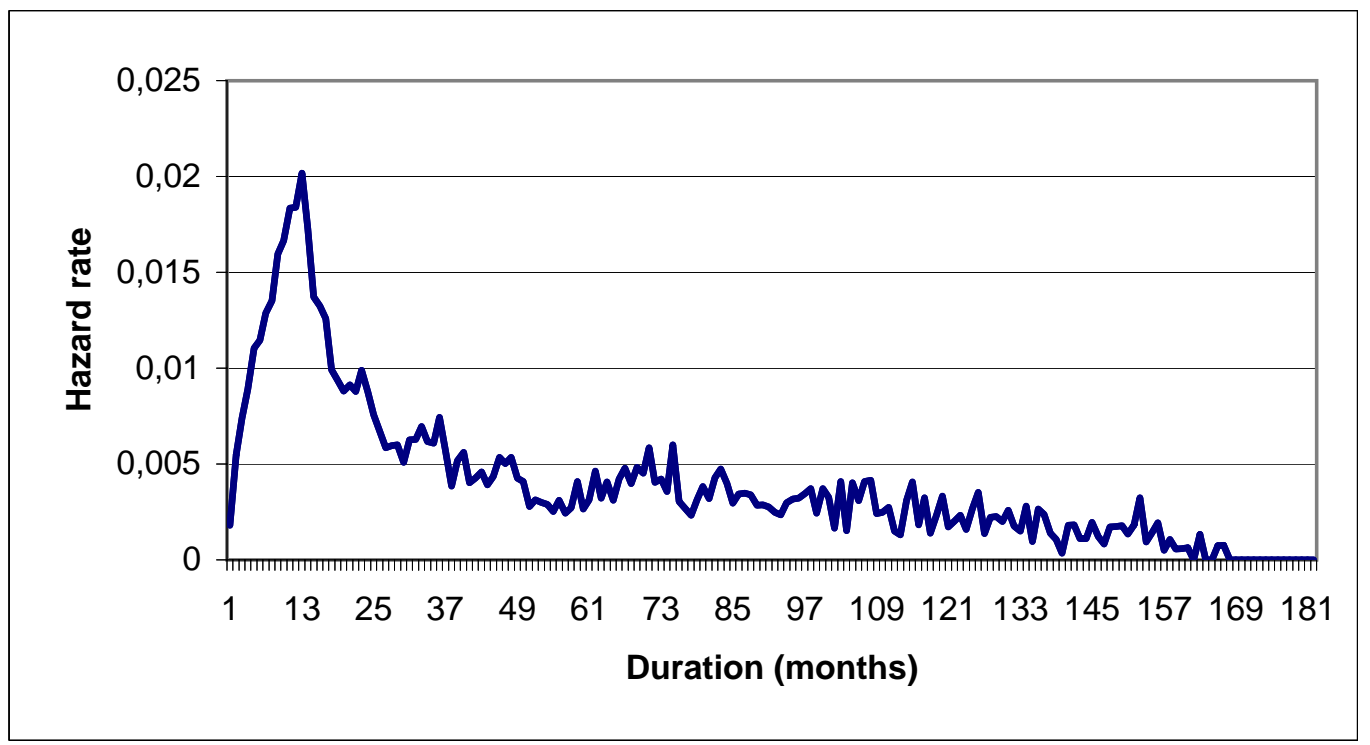

Figure 1. Empirical Hazard Function for Exit from Assigned Municipality

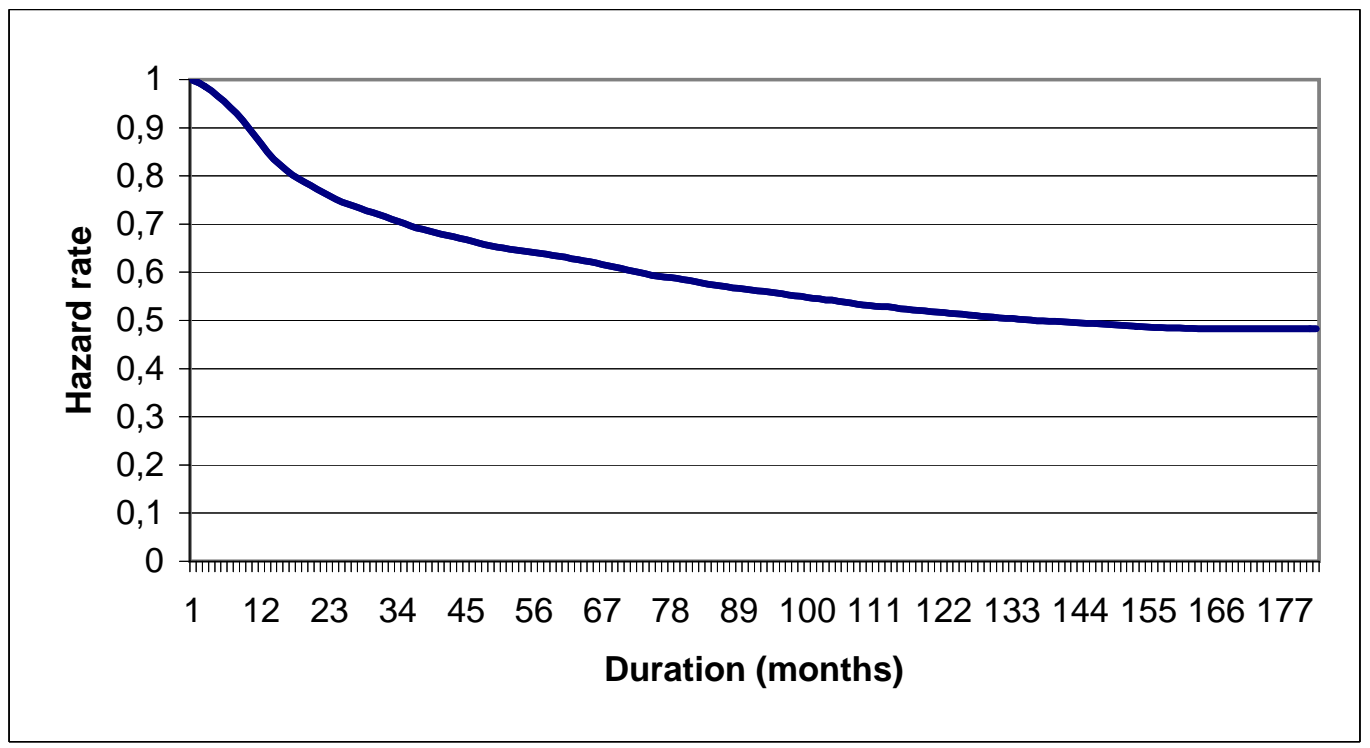

Figure 2. Empirical Survivor Function for Residence in Assigned Municipality 
The empirical hazard function for relocation out of the municipality of assignment is plotted in Figure 1. The empirical hazard function peaks in month 13. The empirical survivor function for residence in the municipality of assignment is plotted in Figure 2. The figure shows that 15 years after initial settlement $48 \%$ of individuals in the sample still live in the assigned municipality.

Furthermore, for each individual we have information on a wide variety of demographic and socioeconomics characteristics of the individual. This allows us to include controls for the personal attributes which may have affected the initial location in the $\mathrm{X}$ vector of personal attributes: marital status, children indicators, age and size of the ethnic stock at the time of immigration as well as year of immigration and country of origin. Another reason for including these personal attributes in the $\mathrm{X}$ vector is that they may affect the expected utility gain and costs of migration. The latter reason is also the reason for which we include sex and years of education in the $\mathrm{X}$ vector. All variables included in the $\mathrm{X}$ vector are defined in Table A.2 and their first two moments are shown in Table A.3 in the Appendix.

\subsection{Descriptive Evidence on Refugees' Initial Settlement and Migration Pattern}

Table 3 shows the initial geographical distribution across counties of refugees in the refugee sample (year of immigration Oct.1985-Dec.1997) and of refugees aged 18-66 who immigrated in the three years prior to the implementation of the spatial dispersal policy. Comparison with the geographical distribution of the overall Danish population shown in Table 1 reveals two facts. First, refugees who immigrated one or two years prior to the implementation of spatial dispersal policy were just like the overall immigrant population highly overrepresented in the Greater Copenhagen area. Second, there is a close correspondence between each county's share of refugees and the population share of the county with one exception, Copenhagen County. This confirms that the dispersal policy was successful in distributing new refugees equally across counties. This is also seen by noting the large drop in the percentage of refugees who initially lived in the Greater Copenhagen area in 1985. The drop occurred already in 1985 because of the dramatic increase in the number of new refugees in 1985 which made it increasingly difficult for the Danish Refugee Council to help new refugees find housing in the Greater Copenhagen area. 


\section{Table 3}

Initial geographic distribution of refugees aged 18-66 across counties.

By year of immigration. Per cent.

\begin{tabular}{lllll}
\hline \hline Year of immigration: & 1983 & 1984 & Jan.-Sept. 1985 & Oct.1985-Dec.1997 \\
\hline County: & & & & \\
Copenhagen \& & & & & \\
Frederiksberg munic. & 23.14 & 29.96 & 10.14 & 10.02 \\
Copenhagen & 12.86 & 8.24 & 7.18 & 6.25 \\
Frederiksborg & 4.86 & 9.49 & 6.23 & 4.93 \\
Roskilde & 2.00 & 0.25 & 1.33 & 2.65 \\
West Zealand & 0.57 & 0.12 & 9.31 & 5.62 \\
Storstroem & 0.00 & 2.00 & 4.04 & 6.13 \\
Bornholm & 0.00 & 0.00 & 0.00 & 0.75 \\
Funen & 23.71 & 7.99 & 12.14 & 11.25 \\
Southern Jutland & 2.00 & 0.25 & 6.16 & 4.75 \\
Ribe & 0.86 & 0.25 & 9.63 & 5.76 \\
Vejle & 2.00 & 0.37 & 9.60 & 8.32 \\
Ringkoebing & 0.86 & 1.75 & 3.78 & 5.04 \\
Aarhus & 22.29 & 25.47 & 8.20 & 12.52 \\
Viborg & 0.57 & 0.00 & 5.88 & 5.29 \\
Northern Jutland & 4.29 & 13.86 & 6.39 & 10.72 \\
All & 100.00 & 100.00 & 100.00 & 100.00 \\
Frequencies & 350 & 801 & 3,147 & 36.718 \\
\hline \hline
\end{tabular}

Source: The immigrant data set and the refugee sample. Note that due to lack of immigrant register data prior to 1984 , the initial distribution across counties of the 1983 cohort refers to its distribution across counties in 1984.

Turning to the extent to which placed refugees migrated subsequently, Table 4 shows that by $199829 \%$ of the refugees in the refugee sample had moved to another county subsequently. Interestingly, the share of migrants from a given county is, in general, close the county's share of placed refugees; this is seen by comparison with Table 2. Funen County and Aarhus County constitute two exceptions by having a smaller share of out-migrants than their share of placed refugees. This indicates that the fraction of out-migrants among placed refugees is approximately equal, around $29 \%$, across counties. The three most populated counties, Copenhagen and Frederiksberg municipalities, Copenhagen County and Aarhus County which together account for $35 \%$ of the Danish population, were the choice of destination for $54 \%$ of the migrants. The migrants mainly come from within the same region. 
Table 4

Migration pattern at the county level for first-time migrants among placed refugees. Per cent of movers from and to each county.

\begin{tabular}{|c|c|c|c|c|c|c|c|c|c|c|c|c|c|c|c|c|}
\hline $\begin{array}{l}\text { County of } \\
\text { destination: } \\
\text { County of } \\
\text { assignment: }\end{array}$ & $\begin{array}{l}\text { Copenhagen \& } \\
\text { Frederiksberg } \\
\text { municipalities }\end{array}$ & $\begin{array}{c}\text { Copen- } \\
\text { hagen }\end{array}$ & $\begin{array}{l}\text { Frederiks- } \\
\text { borg }\end{array}$ & Roskilde & $\begin{array}{c}\text { West } \\
\text { Zealand }\end{array}$ & Storstroem & Bornholm & Funen & $\begin{array}{c}\text { Southern } \\
\text { Jutland }\end{array}$ & Ribe & Vejle & $\begin{array}{c}\text { Ring- } \\
\text { koebing }\end{array}$ & Aarhus & Viborg & $\begin{array}{c}\text { Northern } \\
\text { Jutland }\end{array}$ & $\begin{array}{c}\text { \% of } \\
\text { movers } \\
\text { from } \\
\text { destination: }\end{array}$ \\
\hline Copenhagen & & & & & & & & & & & & & & & & \\
\hline $\begin{array}{l}\text { \& Frederiks- } \\
\text { berg munic. }\end{array}$ & 0 & 7.03 & 1.08 & 0.76 & 0.27 & 0.21 & 0.06 & 0.14 & 0.06 & 0.11 & 0.10 & 0.10 & 0.28 & 0.05 & 0.13 & 10.37 \\
\hline Copenhagen & 5.08 & 0 & 0.51 & 0.75 & 0.05 & 0.06 & 0.04 & 0.08 & 0.05 & 0.04 & 0.06 & 0.05 & 0.06 & 0.01 & 0.04 & 6.86 \\
\hline Frederiksborg & 3.21 & 1.48 & 0 & 0.42 & 0.23 & 0.09 & 0 & 0.11 & 0.02 & 0.03 & 0.10 & 0.04 & 0.13 & 0.02 & 0.13 & 6.01 \\
\hline Roskilde & 1.50 & 1.12 & 0.16 & 0 & 0.13 & 0.18 & 0 & 0.10 & 0.02 & 0.01 & 0.02 & 0 & 0.13 & 0.04 & 0.13 & 3.54 \\
\hline West Zealand & 2.39 & 1.51 & 0.51 & 0.80 & 0 & 0.23 & 0 & 0.31 & 0.10 & 0.26 & 0.27 & 0.27 & 0.60 & 0.11 & 0.19 & 7.54 \\
\hline Storstroem & 1.87 & 1.34 & 0.62 & 0.47 & 0.72 & 0 & 0 & 0.37 & 0.10 & 0.30 & 0.24 & 0.18 & 0.56 & 0.02 & 0.26 & 7.04 \\
\hline Bornholm & 0.04 & 0.03 & 0.03 & 0.02 & 0.07 & 0.02 & 0 & 0.01 & 0.08 & 0 & 0.07 & 0 & 0.04 & 0 & 0.01 & 0.40 \\
\hline Funen & 1.39 & 0.59 & 0.46 & 0.14 & 0.26 & 0.84 & 0 & 0 & 0.47 & 0.37 & 0.84 & 0.31 & 0.85 & 0.17 & 0.22 & 6.91 \\
\hline South. Jutland & 1.26 & 0.38 & 0.25 & 0.21 & 0.17 & 0.08 & 0.01 & 0.64 & 0 & 0.83 & 0.55 & 0.22 & 0.93 & 0.02 & 0.18 & 5.73 \\
\hline Ribe & 1.71 & 0.65 & 0.31 & 0.22 & 0.11 & 0.12 & 0 & 0.74 & 0.48 & 0 & 0.94 & 0.29 & 1.07 & 0.05 & 0.23 & 6.92 \\
\hline Vejle & 1.13 & 0.60 & 0.09 & 0.06 & 0.40 & 0.11 & 0 & 1.21 & 0.44 & 0.52 & 0 & 0.40 & 1.68 & 0.11 & 0.19 & 6.95 \\
\hline Ringkoebing & 0.81 & 0.30 & 0.12 & 0.11 & 0.31 & 0.06 & 0.01 & 0.27 & 0.25 & 0.85 & 0.50 & 0 & 0.68 & 0.11 & 0.16 & 4.68 \\
\hline Aarhus & 1.76 & 0.72 & 0.37 & 0.28 & 0.16 & 0.18 & 0 & 0.63 & 0.46 & 0.52 & 1.83 & 0.49 & 0 & 0.31 & 0.72 & 8.44 \\
\hline Viborg & 1.05 & 0.48 & 0.26 & 0.06 & 0.27 & 0.23 & 0 & 0.52 & 0.35 & 0.37 & 0.79 & 0.57 & 2.10 & 0 & 0.53 & 7.58 \\
\hline North. Jutland & 2.20 & 0.93 & 0.47 & 0.31 & 0.29 & 0.33 & 0 & 0.85 & 0.91 & 0.59 & 0.68 & 0.57 & 2.45 & 0.46 & 0 & 11.03 \\
\hline $\begin{array}{l}\text { \% of movers } \\
\text { to destination }\end{array}$ & 25.40 & 17.15 & 5.24 & 4.60 & 3.44 & 2.74 & 0.11 & 5.98 & 3.76 & 4.80 & 6.99 & 3.48 & 11.55 & 1.62 & 3.14 & 100.00 \\
\hline
\end{tabular}

Source: The refugee sample.

Note: Total number of first-time migrants among placed refugees: 10,491. 


\section{Table 5}

In- and out-migration rates of first-time refugee migrants at the county level.

\begin{tabular}{lllll}
\hline \hline County: & $\begin{array}{l}\text { Number of } \\
\text { placed refugees }\end{array}$ & $\begin{array}{l}\text { Out-migration } \\
\text { rate }\end{array}$ & $\begin{array}{l}\text { In-migration } \\
\text { rate }\end{array}$ & $\begin{array}{l}\text { Net migration } \\
\text { rate }\end{array}$ \\
\hline Copenhagen \& & & & & \\
Frederiksberg munic. & 3,678 & 0.30 & 0.73 & 0.43 \\
Copenhagen & 2,294 & 0.31 & 0.78 & 0.47 \\
Frederiksborg & 1,810 & 0.35 & 0.30 & -0.05 \\
Roskilde & 972 & 0.38 & 0.50 & 0.12 \\
West Zealand & 2,065 & 0.38 & 0.18 & -0.21 \\
Storstroem & 2,249 & 0.33 & 0.13 & -0.20 \\
Bornholm & 276 & 0.15 & 0.04 & -0.11 \\
Funen & 4,130 & 0.18 & 0.15 & -0.02 \\
Southern Jutland & 1,745 & 0.34 & 0.23 & -0.12 \\
Ribe & 2,116 & 0.34 & 0.24 & -0.11 \\
Vejle & 3,056 & 0.24 & 0.24 & 0.00 \\
Ringkoebing & 1,849 & 0.27 & 0.20 & -0.07 \\
Aarhus & 4,596 & 0.19 & 0.26 & 0.07 \\
Viborg & 1,944 & 0.41 & 0.09 & -0.32 \\
Northern Jutland & 3,938 & 0.29 & 0.08 & -0.21 \\
All & 36,718 & 0.29 & 0.29 & 0.00 \\
\hline \hline
\end{tabular}

Source: The refugee sample.

Table 5 reports the out- and in-migration rates of placed refugees relative to the number of refugees initially placed in the county. The out-migration rate is calculated as the share of refugees placed in the county during the observation period who move across the county. The in-migration rate is calculated as the number of first-time movers among placed refugees who move to the county out of the total number of refugees initially placed in the county. It becomes apparent that the migration pattern just described in terms of the initial distribution of refugees implies very high positive net in-migration rates for the two counties in the capital, Copenhagen County and Copenhagen and Frederiksberg municipalites, and a more moderate positive net in-migration rate for Aarhus County in which the second largest city in Denmark, Aarhus, is situated. With one exception, all remaining counties have negative net in-migration rates of first-time movers among placed refugees. 
Table 6

Geographic distribution of subgroups of the Danish population across counties in 2000. Per cent.

\begin{tabular}{llccc}
\hline \hline Subgroup: & All & Immigrants & Pre-reform refugees & Refugee sample \\
\hline County: & & & & \\
Copenhagen \& & & & & \\
Frederiksberg munic. & 11.03 & 25.06 & 27.24 & 16.46 \\
Copenhagen & 11.50 & 17.01 & 13.92 & 8.91 \\
Frederiksborg & 6.88 & 6.94 & 4.92 & 4.42 \\
Roskilde & 4.36 & 3.68 & 2.30 & 2.82 \\
West Zealand & 5.55 & 3.80 & 2.24 & 4.09 \\
Storstroem & 4.85 & 2.88 & 1.85 & 4.52 \\
Bornholm & 0.83 & 0.41 & 0.03 & 0.70 \\
Funen & 8.83 & 7.25 & 11.99 & 11.14 \\
Southern Jutland & 4.73 & 4.02 & 1.59 & 4.07 \\
Ribe & 4.22 & 2.75 & 2.76 & 5.12 \\
Vejle & 6.53 & 4.72 & 3.84 & 8.54 \\
Ringkoebing & 5.11 & 2.96 & 2.98 & 4.60 \\
Aarhus & 11.98 & 11.07 & 17.50 & 13.55 \\
Viborg & 4.37 & 2.03 & 1.65 & 3.33 \\
Northern Jutland & 9.25 & 5.27 & 5.20 & 7.76 \\
All & 100.00 & 100.00 & 100.00 & 100.00 \\
Frequencies & $5,349,212$ & 412,528 & 3,520 & 31,184 \\
\hline \hline
\end{tabular}

Notes: Pre-reform refugees refer to 1983-Oct.1985 cohorts of refugees. Source: The immigrant data set and the refugee sample.

Table 6 presents evidence that the spatial dispersal policy on refugees was successful in augmenting spatial dispersion of refugees relative to other immigrants in the medium run. In 2000, refugees who had been subject to the first Danish spatial dispersal policy were overrepresented in Copenhagen and Frederiksberg municipalities to a much lesser extent than the overall immigrant population and pre-reform refugees and they were in fact underrepresented in Copenhagen County which had the second highest share of immigrants in 2000. In contrast to the overall immigrant population, individuals in the refugee sample were instead slightly overrepresented in the counties in which the second and third largest cities in Denmark are situated, Aarhus County (Aarhus) and Funen County (Odense). Individuals in the refugee sample were only slightly underrepresented in most of the remaining counties. 


\subsection{Area of Origin Data}

Regional attributes of the municipality of assignment which we believe may affect placed refugees' subsequent migration propensity fall into three cateogories: 1) demographic attributes, 2) labour market attributes and 3) housing market attributes.

Concerning demograhic attributes, placed refugees are likely to derive high utility from living in the same location as co-ethnics according to the two hypotheses described in Section 2: 1) the ethnic network hypothesis by Piore (1979) and Kobrin and Speare (1983) and 2) the ethnic goods hypothesis by Chiswick and Miller (2005). These two hypotheses imply that the expected utility gain decreases and the expected costs of migration increase with the size of the ethnic enclave in the municipality of assignment. Therefore, the ethnic enclave size in the municipality of assignment unambigously decreases the migration probability. We follow Bartel (1989) by including the percentage of co-ethnics in the host country living in the municipality of assignment in the $\mathrm{Z}$ vector to capture the relative size of ethnic enclave. This variable is labelled 'PCETH'.

New refugees may prefer international neighbours, possibly for reasons of solidarity. If so, the expected utility gain from migration and migration propensity is likely to decrease with the relative size of the immigrant enclave in the municipality of assignment. To explore this, we include the percentage of immigrants in the host country living in the municipality of assignment in the $\mathrm{Z}$ vector. Trying to capture the effect of presence of immigrants in this way corresponds to the way in which we attempt to capture the effect of presence of co-ethnics. We label the variable 'PCIMM'.

We believe that placed refugees prefer to live in a large city, due to a preference for residing near airports which facilitate contact with old networks abroad, due to access to a large variety of goods and services in general and due to urban populations being more accustomed to interactions with foreigners. If so, current residence in a large city decreases the expected utility gain from migration and increases the expected costs of migration, unambigously decreasing the migration probability. To test this hypothesis, we include the logarithmic value of number of inhabitants in the municipality of assignment in the $\mathrm{Z}$ vector and label it by 'LNPOP'. Similarly, placed refugees may in particular prefer to live in the capital, Copenhagen, due to capital-specific local amenities. If so, initial residence in Copenhagen decreases the net expected utility gain from moving and as a consequence the migration probability. To test this hypothesis, we include an indicator variable for initial residence in the Greater Copenhagen area and label it 'METRO'.

Turning to labour market attributes of the municipality of assignment which may affect placed refugees' migration probability, we believe that refugees prefer living in a location with favourable employment prospects which we believe are negatively correlated with the regional unemployment rate and positively correlated with general economic activity. The 
expected utility gain of migration accordingly increases with the regional unemployment rate and decreases with the general economic activity. As a consequence, the migration probability will increase with the regional unemployment rate and decrease with the general economic activity. To test this hypothesis, we include the regional unemployment rate as a variable in Z and label it 'UNRATE'. To capture the effect of general economic activity, we include the percentage of jobs in the county situated in the municipality of assignment, labelled 'PCJOB'. We believe that there is a positive correlation between these two factors. Note also that inclusion of PCJOB allows us to test the suggestion by Bartel (1989) that her finding that recent immigrants' are attracted to locations with large local populations captures the effect of more job opportunities and higher general economic activity in cities compared to rural and smaller urban areas.

Social assistance rules, including entitlement rules, are the same across Danish municipalities. As a consequence, welfare generosity is unlikely to affect placed refugees' utility levels. However, municipal variation in the administration of social assistance rules may exist, for instance in the extent to which social assistance recipients are required to participate in active labour market programmes. To capture the effect of use of active labour market participation rather than passive income support, we include the percentage of right-wing votes at the local election, labelled 'PCRVOTE', because we believe that rightwing dominated municipalities are more prone to use active labour market participation than left-wing dominated municipalities. We believe that the migration probability increases with PCRVOTE, because some individuals may prefer to leave the municipality of assignment to avoid active labour market training. This effect is similar to the threat effect, i.e. that individuals who are about to be assigned to an active labour market programme tend to begin in an ordinary job in order to avoid programme participation, which has been shown to a major employment-promoting effect of active labour market programmes in Denmark (Rosholm and Svarer 2004).

Education opportunities may be an additional factor affecting recent immigrants', especially refugees', utility levels. First, due to lack of education from the source country. Second, due to lack of approval of foreign educations in the host country. Third, due to a need for upgrading the skill level for employability in the host country labour market, for instance due to a high minimum wage and a mismatch between low-skilled job demand and supply in the host country. In particular, we believe that the expected utility gain from migration decreases with the availability of institutions for attainment of qualifying educations in the municipality of assignment. As a consequence the migration probability decreases with the availability of educational institutions. To capture the availability, we include the number of institutions for qualifying educations in the municipality of assignment, labelled 'EDUCINST'.

Turning to housing market attributes which may affect utility levels of placed refugees, 
such attributes are important to include because relocations out of the municipality of residence may include short-distance relocations which tend to be carried out for housing consumption adjustment reasons. We expect the local residence offer arrival rate to increase with the number of rental units and number of social housing units in per cent of the total local housing stock, because new immigrants in Denmark tend to live in rental housing, especially in social housing. In fact, according to Danish law, immigrants are not allowed to buy property during the first five years of stay in Denmark. The higher the share of rental and social housing units in the municipality of assignment, the lower is the migration probability out of the municipality of assignment likely to be, since adjustment of housing consumption can more easily take place within the municipality of assignment when shares of rental and social housing units are high. We label these two housing variables 'PCRHOUS' and 'PCSHOUS'.

The variables included in the $\mathrm{Z}$ vector are defined in Table A.2 and their first two moments are shown in Table A.3 in the Appendix.

\section{Push Factor Results}

We have estimated six different versions of the MPH model, denoted model 1-6 below. The models differ with respect to which location characteristics variables are included as explanatory variables. In model 1 , we have included three demographic characteristics and one labour market characteristic of the municipality of assignment which have been found to affect immigrants' location choices in previous studies: LNPOP, PCIMM, PCETH and UNRATE. In model 2, one additional demographic characteristic is included: METRO. Relative to model 2, model 3 also contains housing market characteristics: PCSHOUS and PCRHOUS. Relative to model 3, model 4 contains one additional labour market characteristic: PCRVOTE. Relative to model 4, model 5 contains the additional labour market variable: EDUCINST. Finally, model 6 differs from model 5 by having one additional labour market characteristic: PCJOB. The parameter estimates of regional attributes of the municipality of assignment, $\beta_{2}$, are reported for each model in Table $7 .^{3}$

According to model 1, the hazard rate of relocation out of the municipality of assignment significantly decreases with LNPOP and PCETH. Both of these results are in accordance with Bartel (1989), Jaeger (2000) and Åslund (2005). The first result is also in accordance with Zavodny (1999). The latter result is also in accordance with Bauer et al. (2002a; 2002b). In contrast, the hazard rate of relocation out of the municipality of assignment significantly increases with PCIMM. This result contradicts the result found by Zavodny (1999), Jaeger (2000) and Åslund (2005) that recent immigrants are attracted

\footnotetext{
${ }^{3}$ The full set of estimation results are available on request.
} 
to locations in which earlier immigrants live. We will offer a possible explanation for this contradiction at the end of the section. Finally, in accordance with Bartel (1989) but in contradiction to Jaeger (2000), UNRATE is estimated to have an insignificant effect on the hazard rate of relocation.

Turning to model 2, inclusion of METRO only causes insignificant changes in the coefficient estimates of the four variables in $\mathrm{Z}$ which were also included in model 1 . Furthermore, in contrast to our prior beliefs, the hazard rate of relocation out of the municipality of assignment significantly increases with initial residence in Greater Copenhagen. This result does not support our belief that placed refugees have higher utility levels in Greater Copenhagen than else where, on the contrary. A possible explanation for this finding is that relocations out of municipalities in Greater Copenhagen tend to be carried out in order to adjust housing consumption. This is supported by the descriptive evidence shown in Table 3 that cross-county relocations within the Greater Copenhagen area actually account for $29 \%$ of the total cross-county relocations of placed refugees to the Greater Copenhagen area.

However, this explanation is not supported by the estimated model 3. Inclusion of housing market attributes into the model does not make the coefficient of METRO insignificant. In contrast, the coefficient estimate becomes larger and the t-statistic increases. Inclusion of housing market variables instead decreases the coefficient estimate and t-statistic of LNPOP. The interpretation is that refugees prefer living in large cities, partly because it facilitates access to housing. In line with our prior beliefs, the hazard rate of relocation decreases both with PCSHOUS and PCRHOUS.

Turning to model 4, the hazard rate of relocation increases with PCRVOTE. This result supports our prior belief that refugees' utility levels are decreasing in the use of active labour market participation rather than passive income support for unemployed individuals. Inclusion of the variable leaves the coefficient estimates of the location characteristic variables included in model 3 unchanged, except that the coefficient estimate of UNRATE changes sign; it becomes positive, but remains insignificant. It shows that there is a negative correlation between UNRATE and PCRVOTE. 
Table 7

MPH model coefficient estimates.

\begin{tabular}{|c|c|c|c|c|c|c|c|c|c|c|c|c|}
\hline & \multicolumn{2}{|l|}{ Model 1} & \multicolumn{2}{|l|}{ Model 2} & \multicolumn{2}{|l|}{ Model 3} & \multicolumn{2}{|l|}{ Model 4} & \multicolumn{2}{|c|}{ Model 5} & \multicolumn{2}{|c|}{ Model 6} \\
\hline \multicolumn{13}{|c|}{ Demographic attributes: } \\
\hline $\mathrm{LNPOP} / 100$ & -63.135 & $(-50.365)$ & -63.165 & $(-50.189)$ & -43.475 & $(-25.036)$ & -43.501 & $(-24.858)$ & -2.639 & $(-1.121)$ & -1.226 & $(-0.474)$ \\
\hline PCIMM/10 & 0.760 & $(28.716)$ & 0.681 & $(22.121)$ & 0.377 & $(9.372)$ & 0.421 & $(10.203)$ & 0.827 & $(13.950)$ & 0.956 & $(13.130)$ \\
\hline PCETH/10 & -0.271 & $(-10.710)$ & -0.246 & $(-9.441)$ & -0.246 & $(-9.401)$ & -0.254 & $(-9.722)$ & -0.270 & $(-10.195)$ & -0.280 & $(-10.579)$ \\
\hline METRO & - & - & 0.163 & $(4.732)$ & 0.543 & $(14.645)$ & 0.512 & $(13.652)$ & 0.437 & $(10.516)$ & 0.384 & $(8.482)$ \\
\hline \multicolumn{13}{|c|}{ Labour market attributes: } \\
\hline UNRATE/10 & -0.037 & $(-0.779)$ & -0.038 & $(-0.814)$ & -0.073 & $(-1.573)$ & 0.024 & $(0.490)$ & 0.137 & $(2.659)$ & 0.144 & $(2.791)$ \\
\hline PCRVOTE/100 & - & - & - & - & - & - & 0.531 & $(5.794)$ & 0.586 & $(6.332)$ & 0.606 & $(6.518)$ \\
\hline EDUCINST/100 & - & - & - & - & - & - & - & - & -5.383 & $(-11.752)$ & -2.922 & $(-5.230)$ \\
\hline PCJOB/100 & - & - & - & - & - & - & - & - & - & - & -1.231 & $(-5.078)$ \\
\hline \multicolumn{13}{|c|}{ Housing market attributes: } \\
\hline PCSHOUS/100 & - & - & - & - & -1.747 & $(-11.395)$ & -1.540 & $(-9.614)$ & -1.633 & $(-10.170)$ & -1.514 & $(-9.160)$ \\
\hline PCRHOUS/100 & - & - & - & - & -0.762 & $(-4.217)$ & -0.665 & $(-3.670)$ & -1.838 & $(-10.066)$ & -1.875 & $(-9.994)$ \\
\hline
\end{tabular}

Dependent variable: hazard rate of relocation out of assigned municipality.

t-statistics are reported in parentheses.

Controls for demographic and socio-economic characteristics of the individual are included.

Controls for time-invariant unobserved characteristics of the individual are included.

Number of residential spells: 36,718. Number of relocations: 14,326 . 
EDUCINST included in model 5 is seen to be significantly negative, i.e. the hazard of relocation decreases with EDUCINST as we expected. Inclusion of the variable causes significant changes in the coefficient estimate of two of the other location characteristic variables in the model: LNPOP and UNRATE. The coefficient estimate of LNPOP drops substantially and becomes insignificant. The interpretation is that refugees' utility levels increase with local population size, partly because access to educational institutions increases with local population size. The coefficient estimate of UNRATE becomes larger and significantly positive, i.e. now the hazard rate of relocation increases with UNRATE, as we would expect it to do. The interpretation for the coefficient increase is that UNRATE is positively correlated with EDUCINST, but the two factors affect refugees' utility levels in opposite ways.

Turning to the final model, model 6 , the hazard rate of relocation decreases with PCJOB. Specifically, one percentage point increase in PCJOB decreases the hazard rate of relocation by $1 \%\left[(\exp (-1.231 / 100)-1)^{*} 100\right]$. Inclusion of the variable further decreases the coefficient estimate of LNPOP. This supports the suggestion by Bartel (1989) that recent immigrants are attracted to locations with large local populations because of more job opportunities and higher general economic activity in cities compared to rural and smaller urban areas. Inclusion of the variable also decreases the coefficient of EDUCINST, but it remains significant. In particular, one additional institution for qualifying educations decreases the hazard rate relocation by $3 \%\left[(\exp (-2.922 / 100)-1)^{*} 100\right]$. The remaining coefficients of regional attributes are unaffected by the inclusion of PCJOB. Their marginal effects are as follows. One percentage point increase in PCETH decreases the hazard rate by $3 \%[(\exp (-0.28 / 10)-1) * 100]$ ceteris paribus. One percentage point increase in PCIMM increases the hazard rate by $10 \%[(\exp (0.956 / 10)-1) * 100]$ ceteris paribus. METRO increases the hazard rate by $47 \%[(\exp (0.384)-1) * 100]$. One percentage point increase in PCSHOUS decreases the hazard rate of relocation by $1.5 \%\left[(\exp (-1.514 / 100)-1)^{*} 100\right]$. The effect of a corresponding change in PCRHOUS is $2 \%$ [ $(\exp (-1.875 / 100)-1) * 100]$. One percentage point increase in the per cent of right-wing votes increases the hazard rate of relocation by $1 \%[(\exp (0.606 / 100)-1) * 100]$.

Note that the marginal effect of PCETH is robust across model specifications. The marginal effect of PCIMM is fairly robust as well. Note also that LNPOP has an insignificant effect on the hazard rate of relocation, because its effect is captured by the effect of housing and labour market attributes on the hazard rate of relocation. To summarize, refugees prefer living in large cities because it facilitates access to housing, educational institutions and jobs.

The estimated hazard function of the final model, model 6, is plotted in Figure A.1 in the Appendix, for an individual with mean observable and unobservable characteristics. The corresponding estimated survivor function is plotted in Figure A.2 in the Appendix. 
We now return to the issue of the finding that the hazard rate of relocation out of the municipality of assignment significantly increases with PCIMM. Previous empirical studies of immigrants' location choices which have investigated whether location choices are affected by presence of immigrants have chosen to capture the potential effect by inclusion of the number of immigrants in location $j$ in per cent of the number of inhabitants in location $j$ (Zavodny 1999; Jaeger 2000, Åslund 2005). Denote this variable 'foreign born population share' as in (Zavodny 1999). Similarly, let the variable 'ethnic group population share' denote the number of immigrants from an individual's source country in location $j$ in per cent of the number of inhabitants in location $j$. We have instead included PCIMM and PCETH. The reason for this is that we believe that what matters for immigrants' location choices is not 'foreign born population share', or 'ethnic group population share', but rather the size of the immigrant/ethnic enclave in location $j$ relative to the size of immigrant/ethnic enclaves elsewhere in the country. To test this hypothesis, we have estimated a model which differs from model 6 in two aspects: PCIMM and PCETH are substituted by 'foreign born population share' and 'ethnic group population share'. ${ }^{4}$ The estimation results show that the coefficient estimate of 'foreign born population share' is negative but insignificant at conventional significance levels and that the coefficient estimate of 'ethnic group population share' is negative and significant only at a $5 \%$ significance level. Both of these results support our belief that it is the relative size of the immigrant/ethnic enclave that matters for recent immigrants' location choices. Furthermore, inclusion of 'foreign born population share' and 'ethnic group population share' instead of PCIMM and PCETH changes some of the coefficients of the other variables of regional attributes. First, UNRATE changes sign into an insignificant, negative sign. Second, PCJOB changes sign into a significant, positive sign. Both signs contradict our prior beliefs. Third, the coefficient of PCRHOUS turns positive, but insignificant, also in contradiction to our prior belief. Finally, the absolute value of the coefficient of LNPOP increases dramatically, again contradicting the our prior belief that recent immigrants tend to prefer living in large urban areas at least in part because general economic activity as measured by per cent county jobs is larger there than elsewhere. The coefficients of the remaining location characteristics variables are robust to the variable substitution. To conclude the discussion of the effect of presence of immigrants on recent immigrants' location choices, we believe that a relatively large immigrant enclave is in fact a push factor in placed refugees' relocation decision. In general, refugees do not prefer international neighbours, on the contrary. Possible explanations for this finding should be investigated in future research.

\footnotetext{
${ }^{4}$ The estimation results are available on request.
} 


\section{Concluding Remarks}

The results presented in this article give us further insight into the factors affecting recent immigrants' location choices.

First, the results shed light on the question asked in the literature whether recent immigrants prefer living where co-ethnics as well as immigrants from other countries of origin settled earlier. The results presented show that refugees who were assigned to an initial location by the authorities under the terms of the spatial dispersal policy in Denmark carried out from 1986-1998 prefer living where co-ethnics have settled earlier. In contrast, presence of immigrants is in fact a push factor in placed refugees' relocation decision. Explanations for the latter result should be investigated in future research. Furthermore, it should be investigated in the future whether this result holds for all immigrants, irrespective of admission category and cohorts. If so, it has very important implications for research on the causes of ethnic segregation, because it implies that immigrant neighbourhoods in the large cities in Europe and the US with typically many different nationalities are not a consequence of immigrants' preference for international neighbours but instead a consequence of immigrants' restricted neighbourhood choices in the large cities.

Second, the results provide evidence on why recent immigrants are attracted to large cities. The results show that placed refugees prefer living in large cities because it facilitates access to jobs, housing and institutions for attainment of qualifying educations. Third, the results provide evidence on the question raised in the literature whether recent immigrants' location choices are affected by economic factors, in particular employment prospects and welfare generosity. The results show that placed refugees do indeed react to relatively high regional unemployment by moving to another location. However, placed refugees also react to settlement in a right-wing dominated location by moving to another location. This could be due to a wider use of active labour market participation as a requirement for social assistance receipt in right-wing dominated locations rather than passive income support. If so, the result could be interpreted as evidence of welfare seeking.

To the extent that the set of results presented in this paper holds for all admission categories of immigrants, policy makers should expect new immigrants to settle in large cities in neighbourhoods in which earlier cohorts of co-nationals have settled. However, from a labour market assimilation point of view recent immigrants' preference for living with co-ethnics should not necessarily cause policymakers' concern. The high-quality empirical investigation on the effect of living in an ethnic enclave on labour market assimilation of immigrants by Edin et al. (2003) exploits the Swedish spatial dispersal on refugees to take location sorting into account. The results of the study show that residence in an ethnic 
enclave increases earnings of refugees eight years after immigration. The results of the study could well generalize to the labour market assimilation experience of immigrants in other countries.

\section{References}

[1] Bartel, A. 1989. Where do the new immigrants live? Journal of Labor Economics, 7(4): $371-91$.

[2] Bauer, T., G. Epstein and I.N. Gang. 2002a. Enclaves, Language and the Location Choice of Immigrants, IZA Discussion Paper, 558.

[3] Bauer, T., G. Epstein and I.N. Gang. 2002b. Herd Effects or Migration Networks? The Location Choice of Mexican Immigrants in the U.S, IZA Discussion Paper, 551.

[4] Borjas, G.J. 1999. Immigrants and welfare magnets. Journal of Labor Economics, 17(4): 607-637.

[5] Bowles, S. 1970. Migration as investment: Empirical tests of the human investment approach to geographical mobility. Review of Economics and Statistics, 52(4): 356362.

[6] Chiswick, B.R. and P.W. Miller. 2005. Do Enclaves Matter in Immigrant Adjustment? City and Community 4 (1): 5-35.

[7] Coleman, David and Eskil Wadensjö. 1999. Indvandringen til Danmark. Internationale og nationale perspektiver. Viborg: Spektrum.

[8] Damm, A.P. 2005. The Danish Dispersal Policy on Refugee Immigrants 1986-1998: A Natural Experiment? Aarhus School of Business: Department of Economics Working Paper 05-03.

[9] Danish Refugee Council (Dansk Flygtningehjælp). 1986-1994. Annual Reports19861994.

[10] Danish Refugee Council (Dansk Flygtningehjælp). 1993. Om geografisk spredning af asylansøgere, flygtninge og indvandrere. Internal report written by Bente Bondebjerg and Morten Iversen.

[11] Edin, P.-A., P. Fredriksson and O. Åslund. 2003. Ethnic Enclaves and the Economic Success of Immigrants - Evidence from a Natural Experiment, Quarterly Journal of Economics 118: 329-357. 
[12] Elbers, C. and G. Ridder. 1982. True and Spurious Duration Dependence: The Identifiability of the Proportional Hazard Model, Review of Economic Studies 49: 403-410.

[13] Epstein, G.S. 2002. Informational Cascades and Decision to Migrate, IZA working paper 445 .

[14] Heckman, J. and B. Singer. 1984. A Method for Minimizing the Impact of Distributional Assumptions in Econometric Models for Duration Data, Econometrica, 52(2): 271-320.

[15] Jaeger, D.A. 2000. Local Labor Markets, Admission Categories and Immigrant Location Choice. Working Paper, Department of Economics, Hunter College, NY.

[16] Kobrin, F. E., and A. Speare. 1983. Outmigration and ethnic communities. International Migration Review, 17: 425-44.

[17] Lee, E. 1966. A Theory of Migration. Demography, 3(1): 47-57.

[18] Ministry of Internal Affairs (Indenrigsministeriet). 1996. Udlændinge '96. En talmæssig belysning af udlændinge i Danmark. Ch. 6.

[19] Ministry of Internal Affairs (Indenrigsministeriet). 1999. Udlændinge '98. En talmæssig belysning af udlændinge i Danmark.

[20] Nakosteen, R. and M. Zimmer. 1980. Migration and Income: The Question of SelfSelection, Southern Economic Journal 46: 840-851.

[21] Piore, M. J. 1979. Birds of passage: Migrant labor and industrial societies. Cambridge: Cambridge University Press.

[22] Rosholm, M. and M. Svarer. 2004. Estimating the Threat Effect of Active Labour Market Programmes. IZA Discussion Paper 1300.

[23] Sjaastad, L. A.1962. The costs and returns of human migration. Journal of Political Economy, 70: 80-93.

[24] Statistics Denmark 1997. Statistisk Arbog 1997. (Statistical Yearbook 1997).

[25] Zavodny, M. 1997. Welfare and the locational choices of new immigrants. Federal Reserve Bank of Dallas Economic Review, Second Quarter 1997.

[26] Zavodny, M. 1999. Determinants of Recent Immigrants' Locational Choices. International Migration Review 33: 1014-1030. 
[27] Åslund, O. 2005. Now and forever? Initial and subsequent location choices of immigrants. Regional Science and Urban Economics 35: 141-165.

\section{Appendix}

Table A.1 reports the year of immigration and country of origin of individuals extracted from the immigrant data set to the refugee sample. Table A.2 reports the definitions and primary sources of data for the variables used in the empirical analysis. Table A.3 presents means and standard deviations of the variables used in the empirical analysis. Figure A.1 shows the estimated hazard function for exit from the assigned municipality, for an individual with mean observable and unobservable characteristics. The corresponding estimated survivor function is plotted in Figure A.2 
Table A.1

Individuals in the refugee sample.

\begin{tabular}{|c|c|c|c|c|c|c|c|c|c|c|c|c|c|c|}
\hline YEAR: & $1985^{*}$ & 1986 & 1987 & 1988 & 1989 & 1990 & 1991 & 1992 & 1993 & 19994 & 1995 & 1996 & 1997 & TOTAL \\
\hline \multicolumn{15}{|l|}{ CitizEnshiP: } \\
\hline EUROPE: & 61 & 190 & 190 & 188 & 149 & 41 & 0 & 0 & 0 & 76 & 10,372 & 2,473 & 996 & 14,736 \\
\hline Poland & 55 & 171 & 173 & 167 & 0 & 0 & 0 & 0 & 0 & 0 & 0 & 0 & 0 & 566 \\
\hline Rumania & 6 & 19 & 17 & 21 & 149 & 41 & 0 & 0 & 0 & 0 & 0 & 0 & 0 & 253 \\
\hline Bosnia-Herzegovina & 0 & 0 & 0 & 0 & 0 & 0 & 0 & 0 & 0 & 5 & 9,688 & 1,343 & 899 & 11,935 \\
\hline Serbia-Montenegro & 0 & 0 & 0 & 0 & 0 & 0 & 0 & 0 & 0 & 0 & 3 & 25 & 10 & 38 \\
\hline Croatia & 0 & 0 & 0 & 0 & 0 & 0 & 0 & 0 & 0 & 9 & 131 & 16 & 15 & 171 \\
\hline Macedonia & 0 & 0 & 0 & 0 & 0 & 0 & 0 & 0 & 0 & 5 & 39 & 11 & 6 & 61 \\
\hline Slovenia & 0 & 0 & 0 & 0 & 0 & 0 & 0 & 0 & 0 & 6 & 9 & 6 & 7 & 28 \\
\hline Yugoslavia & 0 & 0 & 0 & 0 & 0 & 0 & 0 & 0 & 0 & 51 & 502 & 1,072 & 59 & 1,684 \\
\hline AFRICA: & 14 & 70 & 44 & 17 & 97 & 88 & 241 & 244 & 441 & 305 & 298 & 439 & 293 & 2,591 \\
\hline Ethiopia & 14 & 70 & 44 & 17 & 27 & 15 & 12 & 17 & 11 & 41 & 12 & 12 & 9 & 301 \\
\hline Somalia & 0 & 0 & 0 & 0 & 70 & 73 & 229 & 227 & 430 & 264 & 286 & 427 & 284 & 2,290 \\
\hline Uganda & 0 & 0 & 0 & 0 & 0 & 0 & 0 & 0 & 0 & 0 & 0 & 0 & 0 & 0 \\
\hline AMERICA: & 6 & 11 & 12 & 8 & 0 & 0 & 0 & 0 & 0 & 0 & 0 & 0 & 0 & 37 \\
\hline Chile & 6 & 11 & 12 & 8 & 0 & 0 & 0 & 0 & 0 & 0 & 0 & 0 & 0 & 37 \\
\hline ASIA: & 765 & 2,731 & 1,161 & 1,093 & 1,125 & 1,013 & 1,130 & 1,324 & 985 & 592 & 861 & 862 & 833 & 14,475 \\
\hline Afghanistan & 11 & 31 & 11 & 16 & 27 & 37 & 87 & 47 & 55 & 71 & 101 & 110 & 112 & 716 \\
\hline Iraq & 123 & 256 & 145 & 279 & 274 & 216 & 240 & 599 & 508 & 265 & 487 & 474 & 529 & 4,395 \\
\hline Iran & 508 & 770 & 630 & 603 & 429 & 365 & 384 & 225 & 164 & 94 & 66 & 167 & 137 & 4,542 \\
\hline Sri Lanka & 97 & 1,534 & 292 & 18 & 45 & 37 & 98 & 104 & 83 & 112 & 150 & 67 & 28 & 2,665 \\
\hline Vietnam & 26 & 140 & 83 & 177 & 350 & 358 & 321 & 349 & 175 & 50 & 57 & 44 & 27 & 2,157 \\
\hline No CITIZENSHIP: & 258 & 1,290 & 794 & 481 & 616 & 354 & 395 & 472 & 67 & 45 & 42 & 34 & 31 & 4,879 \\
\hline TOTAL: & 1,104 & 4,292 & 2,201 & 1,787 & 1,987 & 1,496 & 1,766 & 2,040 & 1,493 & 1,018 & 11,573 & 3,808 & 2,153 & 36,718 \\
\hline
\end{tabular}

* From October 1985 to December 1985 
Table A.2. Part A.

Variable definitions and primary sources of data.

\begin{tabular}{|c|c|c|}
\hline Variable & Definition & Primary source of data \\
\hline \multicolumn{3}{|c|}{ Individual characteristics: } \\
\hline Sex & Dummy for sex. & $\begin{array}{l}\text { Population register, } \\
\text { Statistics Denmark (DST). }\end{array}$ \\
\hline Age & Age. & Population register, DST. \\
\hline Married & Dummy for being married. & Population register, DST. \\
\hline Children aged 0-2 & $\begin{array}{l}\text { Dummy for presence of children } \\
\text { between } 0 \text { and } 2 \text { years of age } \\
\text { in the household. }\end{array}$ & Population register, DST. \\
\hline Children aged 3-17 & $\begin{array}{l}\text { Dummy for presence of children } \\
\text { between } 3 \text { and } 17 \text { years of age } \\
\text { in the household. }\end{array}$ & Population register, DST. \\
\hline Country of origin & Dummy for immigrant source country. & Population register, DST. \\
\hline Year of immigration & $\begin{array}{l}\text { Dummy for first year of receipt of } \\
\text { residence permit. }\end{array}$ & Population register, DST. \\
\hline Years of education & $\begin{array}{l}\text { Number of years of education prior } \\
\text { to immigration constructed from } \\
\text { an education code of highest } \\
\text { degree attained prior to immigration. }\end{array}$ & $\begin{array}{l}\text { Surveybased register on } \\
\text { immigrants' education level } \\
\text { attained prior to immigration, DST. }\end{array}$ \\
\hline Ethnic stock & $\begin{array}{l}\text { Number of immigrants and } \\
\text { descendants of immigrants from } \\
\text { immigrant source country in Denmark. }\end{array}$ & $\begin{array}{l}\text { Population register, DST. } \\
\text { Author's calculations based on } \\
100 \text { per cent sample of immigrants. }\end{array}$ \\
\hline
\end{tabular}

Municipality characteristics:

METRO

Dummy for residence in Copenhagen

Population register, DST.

or Frederiksberg municipalities or in

Copenhagen County.

POP

Number of inhabitants in municipality $j$.

Population statistics

(population counted data), DST.

PCIMM

Number of immigrants and descendants

Population register, DST.

of immigrants residing in municipality $j$

Author's calculations based on

in per cent of the total number of

100 per cent sample of immigrants.

immigrants and descendants in Denmark. 
Table A.2. Part B.

Variable definitions and primary sources of data.

\begin{tabular}{|c|c|c|}
\hline Variable & Definition & Primary source of data \\
\hline \multicolumn{3}{|c|}{ Municipality characteristics } \\
\hline PCETH & $\begin{array}{l}\text { Number of immigrants and descendants } \\
\text { of immigrants from source country } k \\
\text { residing in municipality } j \text { in per cent of } \\
\text { the total number of immigrants and } \\
\text { descendants from source country } k \text { in } \\
\text { Denmark. }\end{array}$ & $\begin{array}{l}\text { Population register, DST. } \\
\text { Author's calculations based on } \\
100 \text { per cent sample of immigrants. }\end{array}$ \\
\hline UNRATE & $\begin{array}{l}\text { The unemployment rate in a radius } \\
\text { of DKK } 60 \text { (approx. USD 10) } \\
\text { of transport around the largest } \\
\text { post office in municipality } j \text {. }\end{array}$ & $\begin{array}{l}\text { Unemployment register } \\
\text { (population counted data), DST, } \\
\text { and cost of transport statistics, } \\
\text { the Ministry of Transport. } \\
\text { Constructed by Local } \\
\text { Government Studies. }\end{array}$ \\
\hline PCRVOTE & $\begin{array}{l}\text { Sum of votes for the Liberal Party and } \\
\text { the Conservative People's Party in per } \\
\text { cent of the sum of votes for the Liberal } \\
\text { Party, the Conservative People's Party, } \\
\text { the Social Democratic Party and } \\
\text { the Socialist People's Party } \\
\text { at the latest municipal election. } \\
\text { The two former parties are traditional, } \\
\text { right-wing parties whereas the latter } \\
\text { two are traditional, left-wing parties. }\end{array}$ & Election statistics, DST. \\
\hline EDUCINST & $\begin{array}{l}\text { Number of institutions for vocational } \\
\text { and higher education in municipality } j \text {. }\end{array}$ & $\begin{array}{l}\text { Integrated pupil register } \\
\text { (population counted data), DST. }\end{array}$ \\
\hline PCJOB & $\begin{array}{l}\text { Number of individuals employed } \\
\text { in municipality } j \text { in per cent of } \\
\text { the total number of individuals } \\
\text { employed in the county. }\end{array}$ & $\begin{array}{l}\text { Registerbased labour force } \\
\text { statistics (population counted } \\
\text { data), DST. }\end{array}$ \\
\hline PCSHOUS & $\begin{array}{l}\text { Number of social housing dwellings } \\
\text { for all-year residence in per cent of the } \\
\text { total number of dwellings } \\
\text { for all-year residence in municipality } j \text {. }\end{array}$ & $\begin{array}{l}\text { Buildings and housing statistics } \\
\text { (population counted data), DST. }\end{array}$ \\
\hline PCRHOUS & $\begin{array}{l}\text { Number of rental housing dwellings } \\
\text { for all-year residence in per cent of the } \\
\text { total number of dwellings } \\
\text { for all-year residence in municipality } j \text {. }\end{array}$ & $\begin{array}{l}\text { Buildings and housing statistics } \\
\text { (population counted data), DST. }\end{array}$ \\
\hline
\end{tabular}


Table A.3. Part A.

Summary statistics (initial values).

\begin{tabular}{l|ll}
\hline \hline Variables & Mean & Std. dev. \\
\hline Woman & 0.41 & 0.49 \\
Age & 32.19 & 12.11 \\
Married & 0.54 & 0.50 \\
Children 0-2 years & 0.19 & 0.46 \\
Children 3-17 years & 0.65 & 1.15 \\
Country of origin: & & \\
Poland & 0.02 & 0.12 \\
Iraq & 0.12 & 0.33 \\
Iran & 0.12 & 0.33 \\
Vietnam & 0.06 & 0.24 \\
Sri Lanka & 0.07 & 0.26 \\
No citizenship & 0.13 & 0.34 \\
Ethiopia & 0.01 & 0.09 \\
Afghanistan & 0.02 & 0.14 \\
Somalia & 0.06 & 0.24 \\
Rumania & 0.01 & 0.08 \\
Chile & 0.001 & 0.03 \\
Former Yugoslavia & 0.05 & 0.21 \\
Bosnia-Herzegovina & 0.33 & 0.47 \\
Ex-Yugoslavia (excl. BH) & 0.01 & 0.09 \\
years of education: 9-12 & 0.17 & 0.38 \\
years of education $>12$ & 0.13 & 0.34 \\
Years of education missing & 0.62 & 0.49 \\
\hline \hline
\end{tabular}


Table A.3. Part B.

Summary statistics (initial values). Means (std. dev.).

\begin{tabular}{l|ll}
\hline \hline Variables & Mean & Std. dev. \\
\hline Immigration year 1985 & 0.03 & 0.17 \\
Immigration year 1986 & 0.12 & 0.32 \\
Immigration year 1987 & 0.06 & 0.24 \\
Immigration year 1988 & 0.05 & 0.22 \\
Immigration year 1989 & 0.05 & 0.23 \\
Immigration year 1990 & 0.04 & 0.20 \\
Immigration year 1991 & 0.05 & 0.21 \\
Immigration year 1992 & 0.06 & 0.23 \\
Immigration year 1993 & 0.04 & 0.20 \\
Immigration year 1994 & 0.03 & 0.16 \\
Immigration year 1995 & 0.32 & 0.47 \\
Immigration year 1996 & 0.10 & 0.31 \\
Immigration year 1997 & 0.06 & 0.24 \\
Ethnic stock & 10,171 & 5,718 \\
Municipality of residence: & & \\
POP & 98,446 & 135,970 \\
PCIMM & 3.19 & 6.29 \\
PCETH & 4.11 & 6.65 \\
METRO & 0.16 & 0.37 \\
UNRATE & 9.69 & 2.32 \\
PCRVOTE & 42.74 & 13.21 \\
EDUCINST & 7.84 & 9.79 \\
PCJOB & 22.73 & 25.40 \\
PCSHOUS & 19.70 & 11.20 \\
PCRHOUS & 43.29 & 15.88 \\
Number of observations & 36,718 & \\
\hline \hline
\end{tabular}




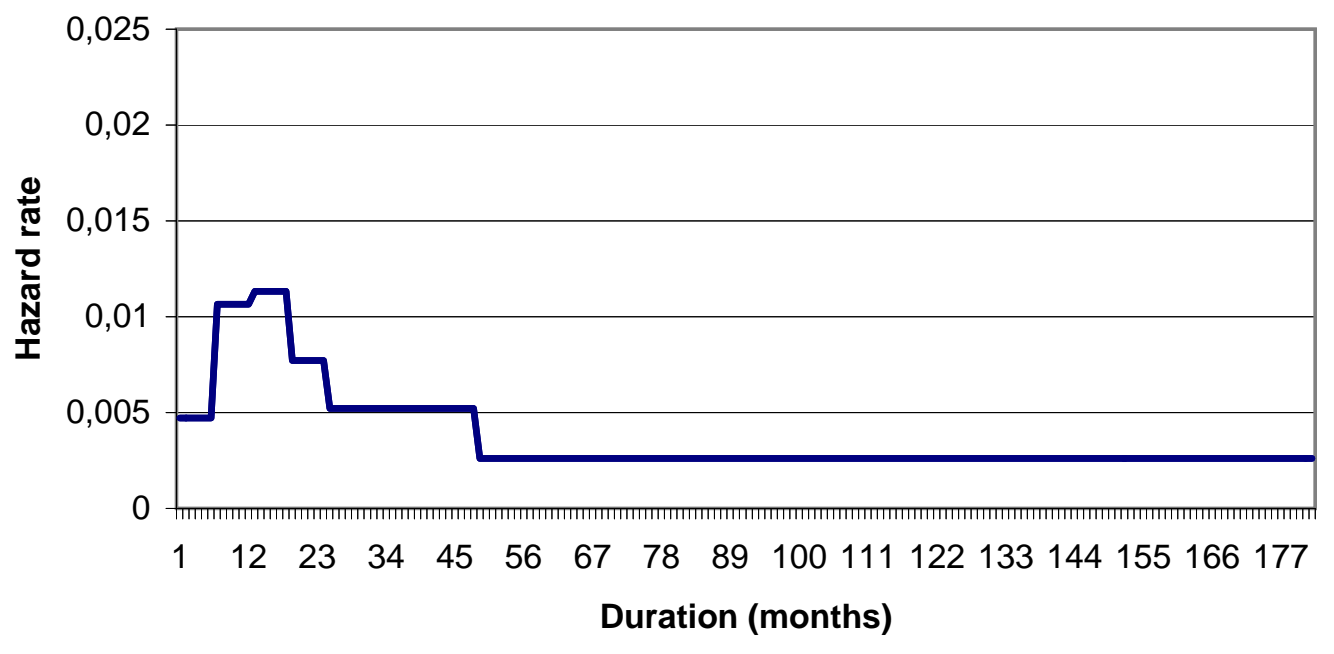

Figure A.1. Estimated Hazard Function for Exit from Assigned Municipality.

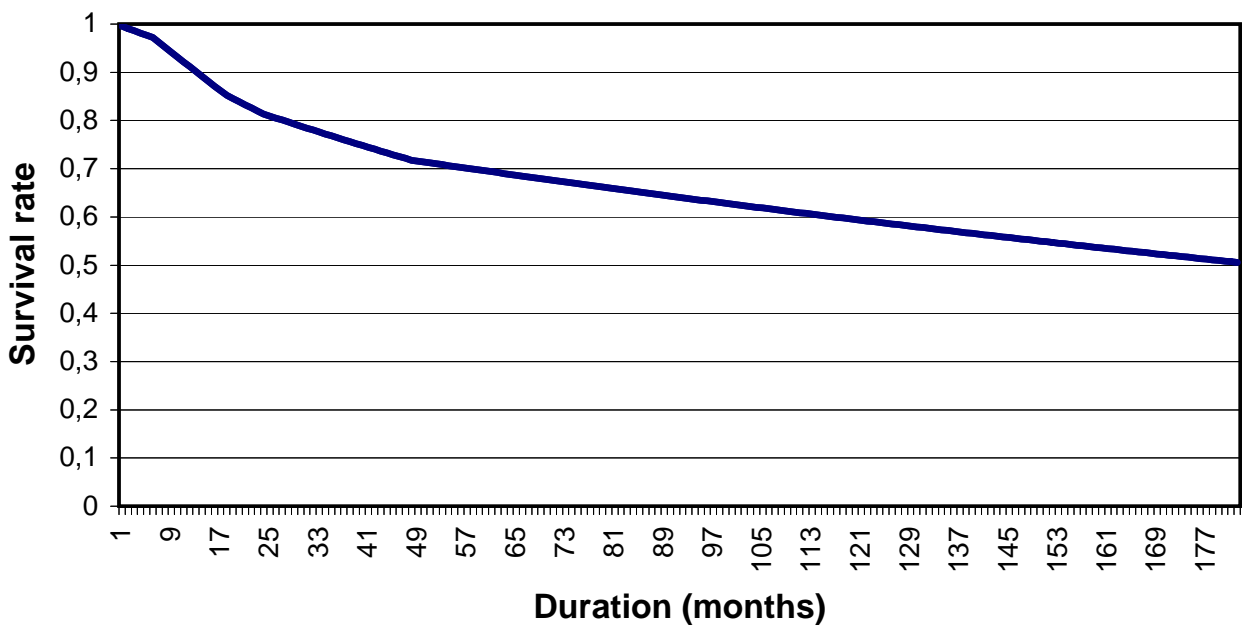

Figure A.2. Estimated Survivor Function for Residence in Assigned Municipality. 